similar to trocar tubes and are partially sharpened. One of proper size is selected and placed on the skin over the site of the powder grain and then it is pressed down so that on removal the skin together with the powder grain is elevated above the surrounding skin. It can then be snipped off with a pair of fine curved scissors and a suture of fine black skin allows the wound to heal by first intention without leaving any scar.

S. N. N.

\section{CINCINNATTI LETTER.}

(FROM OUR OWN CORRESPONDENT.)

The Association Meeting in May-More Positions for Internes in the Cincinnati Hospital-The Hospital; the Staff-Coalescence of Medical Societies-Fire in the Cincinnati Hospital-Medical College Commencements.

The absorbing topic in medical circles here is the meeting of the American Medical Association in our city in May of this year. We confidently prophecy a very successful meeting, at least so far as the efforts of the local men are concerned. It has been twenty years since we were honored by having the Association meet here, and we therefore wish to make the session a grand success. The various committees are busily engaged pushing forward the work allotted to them. Music Hall and the adjoining rooms have been secured for the meetings. This building is admirably fitted for the general meeting, and also for the meetings of the various Sections.

There will be a banquet tendered the members at our magnificent new Art Museum, at which place the delights of the stomach may be readily combined with those works of art that are so delightful to the ey e. Thus we may be enabled to obtain a feast of vision and a flow of gastric juice. The following evening will be devoted to a concert given by the Apollo Club, at Music Hall. We can guarantee a hearty and cordial welcome to all, and trust that we may be honored by an unusually large attendance.

The hospital authorities have increased the chances for men to obtain hospital training, by appointing seven externes in addition to the internes already on duty. The applicants for the positions are subjected to a competitive examination. The seven presenting the best papers in all branches are chosen to fill the positions. These examinations are strictly impartial, the Staff not knowing whose paper they examine nor in whose favor they vote. The externes are chosen about the first of October each year, becoming internes upon the roth of the following April. Thus during the winter months there are fifteen men on duty; seven internes, one senior interne, and seven externes. The new system of appointing externes was inaugurated last Fall, and must still be considered in the nature of an experiment.

The City Hospital is a public institution, capable of holding about 400 patients. The government is vested in a Board of Trustees appointed by the Governor of the State and by the Superior Court. Politics have never had any influence in the distribution of positions, either medical or executive; conse- quently the institution has always been well conducted and prosperous.

The Medical Staff of the Hospital consists of four surgeons, four medical men, four obstretricians, two oculists, two pathologists, and four curators and microscopists. The last named are not official positions. The Staff changes every four months; half of the men being on duty at all times. Such men as the following constitute the Staff: Drs. N. P. Dandridge, P. S. Conner, E. W.Walker, Jos. Ransohoff, surgeons; Drs. J. A. Murphy, F. Farcheheimer, J. C. Mackenzie and $\mathrm{Wm}$. Carson, are the medical staff. The obstetricians are Drs. W. H. Taylor, Thad. Reamy, C. D. Palmer, and G. M. Allen. The oculists are Drs. Jos. Aub and Rob't Sattler. Pathologists, Drs. Kebler and Eichberg. Drs. Marsh, Cameron, Holmes and Caldwell occupy positions as curators.

Several years ago an agitation arose that resulted in a division in the Academy of Medicine and a new Society was organized. The consequence of the division was that the medical profession of our city has been seriously hampered and crippled by a lack of unity. There has been no assembly that authoritatively represented the opinions of the medical profession as a whole. Two comparatively weak Societies have been holding forth in place of one large, powerful and united brotherhood. Happily, the schism is about at an end. The propriety and feasibility of the amalgamation of the two Societies has been freely discussed, and the general tenor of opinion is decidedly in favor of an early coalescence. The advantages that will arise from such a course are very obvious. We shall be a united, harmonious and truly powerful association; we can speedily obtain a permanent home for ourselves; we can be influential in securing legislation for the good of the public and for our own advancement; and better work can be done.

There has been quite a serious conflagration at the Cincinnati Hospital. The fire originated in a very peculiar manner, but one that it would be well to detail, as other institutions may have similar deathtraps for their patients. An elevator formerly run up through a shaft at the south end of the burned pavilion; after the elevator was removed the shaft was divided into compartments through which the dirty clothes, dust, etc., were carried to the basement. Just alongside of this chute, in the first story of the building, was a gas-stove. There had been a leak in the gas-pipe and the gas escaped up this chute to the ventilating space between the ceiling and the roof. A match was applied to the gas-stove, with the effect of igniting the gas which had accumulated in the shaft ; an explosion followed, setting fire to the woodwork and largely destroying the entire third floor of the pavilion. The patients all escaped without injury, but their safety was largely due to the efforts of Dr. H. T. Gaylord, an interne, and Mr. Julius Eichberg, the apothecary of the institution. Others deserve great credit for their efforts in rescuing the badly frightened patients, but the above named were on hand at the time of the explosion and therefore had a better opportunity for distinction.

The burned pavilion is the only one that is not 
possessed of exits at both ends. As the fire originated near the staircase, the patients were somewhat panicstricken. The damage to the institution will be immediately repaired, and the previous defects in architecture will be remedied. Five thousand dollars will about cover the amount of damage done.

The medical colleges have had their commence ment exercises. An interesting feature of the graduation exercises of the Ohio College was an address delivered by Dr. J. S. Billings, of Washington, D. C., on "A History of the Ohio Medical College before the War." It was a very interesting and pleasant talk, quite out of the line of the ordinary set speeches we are so apt to have inflicted upon us at Commencements. He spoke in eloquent terms of Drs. Graham and Blackman, recently deceased.

J. C. O.

\section{ENORMOUS ENLARGEMENT OF THE HEAD.}

Dear Sir :-The following case may be of interest to the readers of THE Journal:

Isham Harris, colored, æt. I 7. Has been under my observation for 5 years. At the age of 3 months he had an eruption of the scalp lasting 6 months, during which the occiput, parietal and occipitofrontalis bones began to enlarge ard have gained the enormous size of 33 inches above the ears, $171 / 2$ inches each side right and left from chin to top of head. He is of average intelligence, sews, knits and crochets, has the physical development and face of a 5 years' old child, has not walked any in 7 years, previously having walked on crutches and getting a fall has since refused to make the attempt. His general health is good and has been from infancy. Has slight headache and dizziness when his liver is torpid, otherwise never complains of weight, pain or any unnatural feeling about the head, and weighs 85 pounds. I made a fruitless attempt to get his photograph to present at the International Medical Congress, and have not succeeded at this writing, his mother refusing, stating that she is afraid someone will kidnap him for public exhibition.

R. H. Jenkins, M.D.

Hogansville, Ga.

NATIONAL CONTROL OF QUARANTINE.

Dear Sir:-The editorial in your issue of the $24^{\text {th }}$ inst. entitled "The Bill (H. R. I526) to Prevent the Introduction of Contagious and Infectious Diseases and to Establish a Bureau of Health," causes me to understand that you have the impression that this is a bill which was introduced through the agency of the committee of the College of Physicians of Philadelphia. I write this, as a member of that committee, for the purpose of removing that impression. The bill you speak of is doubtless one which has been proposed and introduced in accordance with the action of the American Public Health Association, at their last meeting, in advocacy of the establishment of a National Bureau of Health, and the Philadelphia committee have had no connection with it in any way. The report and the recommendation of our committee were strictly limited to the question of the necessity of National Control of the Maritime Quarantine, and the bill embodying the suggestions made in our address to the medical societies of the country has not yet been introduced. May I request that you publish this letter, in order to correct a similar impression which may have been received by others? Very respectfully, E. O. Shakespeare.

1336 Spruce St., Philadelphia, March 26, I888.

\section{A CASE OF POST-PARTUM PUERPERAL CONVULSIONS.}

Dear Sir:-On February 22, 1888, I was called by her husband to see Mrs. B., æt. 24, multipara, whom $I$ found in labor. The labor had advanced to the second stage, and she was delivered in about thirty minutes after my arrival of a well-developed male fotus. The labor was normal in every respect, and there was no hæmorrhage nor laceration of cervix or perineum. She had been in good health prior to labor, with the exception of the last three days, during which she had suffered from a very severe throbbing headache. After delivery this headache continued, and about thirty minutes after delivery was completed she suddenly passed into general convulsions. In the course of an hour and a half she had seven very severe convulsive attacks. I sent for counsel at once, which, however, did not reach me until after the convulsions had ceased. Immediately after the first attack passed off I injected hypodermically $1 / 2$ gr. morphia with ${ }_{5} 0$ gr. atropia, which producing no visible effect, in thirty minutes I injected $3 / 8$ gr. morphia with $\frac{3}{200}$ gr. atropia, and bled her from the arm to about 12 ozs. After the second injection and the venesection the convulsions were less violent and the intervals longer, but as they had not ceased one hour after the second injection of morphia and atropia, I made an injection of $1 / 4 \mathrm{gr}$. morphia alone. In a few minutes the convulsions ceased and did not recur. The patient remained in an unconscious state about nine hours after the last convulsion, when she gradually regained consciousness, and has made a good recovery.

The patient is a stout, plethoric woman, and before the venesection the pulse was full, hard and bounding.

C. J. MARCH, M.D.

Whelan Springs, Ark., March \&, i 888 .

\section{NECROLOGY.}

\section{A. B. STUART, M.D.}

Dr. A. B. Stuart died at Santa Rosa, California, on July 30 , I 887 , aged 57 years.

Dr. Stuart was born at Williamsburg, Pa., on August 27,1830 . He was educated at Lewisburg University, Pa., and entered upon the study of medicine at Berkshire Medical College, Pittsfield, Mass., from which institution he was graduated M.D. in November, 1856. Previous to his graduation he 